\title{
Kinetics and bioavailability of two formulations of amiloride in man
}

\author{
A. J. SMITH AND R. N. SMITH
}

Section of Therapeutics, Academic Division of Medicine, University of Sheffield, Royal Infirmary, Sheffield, S6 3DA

\section{Summary}

1. Two formulations of $\left[{ }^{14} \mathrm{C}\right]$-amiloride were compared in six oedema-free subjects in single-dose $(20 \mathrm{mg})$ studies separated by a two-week interval.

2. Calculation of the elimination rate constant $\left(\mathrm{K}_{\mathrm{e}}\right)$, half-life $\left(T_{\mathrm{t}}\right)$ and apparent volume of distribution $\left(V_{d}\right)$ from serum and urinary data showed no significant difference between the two formulations. The $V_{d}$ values (350 to 380 litres) were greater than total body fluid volume suggesting extravascular sequestration of amiloride.

3. Serum and urinary amiloride levels were similar with both formulations. Pharmacokinetic parameters were similar to those of an earlier report based on one formulation.

4. The calculated amiloride concentration in the renal distal tubule $(3 \mu \mathrm{M}$ to $20 \mu \mathrm{M}$ ) was similar to, but higher than, reported in vitro concentrations of amiloride which reduced sodium transport in isolated membranes.

\section{Introduction}

Amiloride is an effective natriuretic and diuretic compound which also reduces urinary potassium loss (Baer, Jones, Spitzer \& Russo, 1967 ; Baba, Lant, Smith, Townshend \& Wilson, 1968). In the course of a study of the bioavailability of two different formulations of amiloride, an opportunity was provided to confirm earlier work on its clinical pharmacology (Weiss, Hersey, Dujovne \& Bianchine, 1969) and to compare effective urinary concentrations of the diuretic in man with those required to inhibit sodium transport in animal tissues in vitro.

\section{Methods}

The two formulations of amiloride were administered in random sequence to six oedema-free subjects in single-dose studies separated by a two-week interval.

\section{Subjects}

There were six male subjects, aged 35 to 56 years (mean 49 years) without cardiovascular, renal or hepatic disease. Four convalescent patients, who had had orthopaedic operations at least four weeks previously, agreed to participate in the study. The other two subjects were healthy members of departmental staff. 


\section{Amiloride preparations}

Amiloride hydrochloride $(5 \mathrm{mg})$ tablets labelled with ${ }^{14} \mathrm{C}(2 \cdot 5 \mu \mathrm{C}$.) in the guanidine side-chain were provided. One formulation (8810) contained tartaric acid and guar gum among the inert ingredients; these were omitted from the other formulation (8811).

\section{Procedure}

The subjects swallowed four tablets $(20 \mathrm{mg})$ of ${ }^{14} \mathrm{C}$-labelled amiloride $(10 \mu \mathrm{Ci})$ after an overnight fast and emptying the bladder. Venous blood samples $(15 \mathrm{ml})$ were taken before dosing (zero time), at 1, 2, 3, 4, 5, 7, 10, 12, 24 and $48 \mathrm{~h}$ after administration. Serum samples were separated and deep frozen. Urine collections were made for the following intervals: $0-2,2-4,4-6,6-8,8-12,12-24,24-48$ and 48-72 hours. Faeces passed within the 72 h period were collected. All specimens were stored at $-20^{\circ} \mathrm{C}$.

After a two-week interval the study was repeated with the other formulation. No other drugs were taken throughout the study and food was permitted three hours after dosing.

\section{Estimations}

Radioactivity in duplicate serum and urine aliquots was measured directly in a liquid scintillation spectrometer (Packard) with an internal standard. A preliminary extraction step was not necessary (Weiss et al., 1969). Faecal radioactivity was measured on pooled, homogenized aliquots of the 72-h collections in a sample oxidizer (Packard). Sodium, potassium and creatinine levels in serum and urine were estimated using standard auto-analyser (Technicon) methods.

\section{Kinetic analyses}

The elimination rate constant $\left(\mathrm{K}_{\mathrm{e}}\right)$, half-life $\left(T_{\mathfrak{\xi}}\right)$ and apparent volume of distribution $\left(V_{d}\right)$ were calculated from serum and urinary data. Amiloride is not metabolized in man and unexcreted drug was also calculated from urinary data. Thus, the $\mathrm{K}_{\mathrm{e}}$ and $T_{1}$ were estimated from serum data and unexcreted drug levels by least squares fit giving two estimates of each parameter (Wagner, 1971). It was also possible to calculate the $V_{d}$ from the renal clearance $\left(f . K_{0} . V_{d}\right)$ where $f$ is the ratio of urinary excretion to total recovery.

\section{Results}

\section{Comparative kinetic analysis on the two formulations}

The serum levels of labelled amiloride and urinary excretion expressed as a percentage of total dose ingested showed individual variations on the two formulations. Serum data were less satisfactory as radioactivity was close to background and total recovery was not complete in 3 of the 12 studies. However, comparison of the cumulative urinary excretion of amiloride showed no significant difference between the two formulations; data available from authors on request.

The $\left(T_{1}\right)$ values calculated from urine and serum data confirmed that both formula- 
tions were handled similarly (Tables 1 and 2). Values for $V_{d}$ were less precise but eight studies with reliable serum data gave $V_{a}$ figures ranging between 350 and 380 litres and no difference between the two formulations.

TABLE 1. Comparison of elimination rate constant $\left(K_{e}\right)$ and half-life $\left(T_{\mathfrak{l}}\right)$ values for two amiloride formulations (8810 and 8811) derived from urinary data

\begin{tabular}{|c|c|c|c|c|}
\hline \multirow[b]{3}{*}{$\begin{array}{c}\text { Subject } \\
1 \\
2 \\
3 \\
4 \\
5 \\
6\end{array}$} & \multirow{2}{*}{\multicolumn{3}{|c|}{ Formulation }} & \multirow{2}{*}{8811} \\
\hline & & & & \\
\hline & $\begin{array}{c}\mathbf{K}_{\mathrm{e}}(\text { per } \mathrm{h}) \\
\mathbf{0 . 0 8 6 9} \\
0.0732 \\
0.0661 \\
0.0806 \\
0.0671 \\
0.0980\end{array}$ & $\begin{array}{r}T(\mathrm{~h}) \\
7.97 \\
9 \cdot 47 \\
10.48 \\
8.60 \\
10.33 \\
7.07 \\
9.88\end{array}$ & $\begin{array}{c}\mathrm{K}_{\mathrm{e}}(\text { per h) } \\
0.0813 \\
0.0612 \\
0.0640 \\
0.0843 \\
0.0784 \\
0.0736\end{array}$ & $\begin{array}{r}T_{\mathbf{t}}(\mathrm{h}) \\
8.52 \\
11 \cdot 32 \\
10 \cdot 83 \\
8 \cdot 22 \\
8 \cdot 84 \\
9 \cdot 42 \\
9^{\prime} 53\end{array}$ \\
\hline
\end{tabular}

Paired $t$ test $\left(T_{\frac{1}{2}}\right.$ values $)=0.83$ (not significant).

TABLE 2. Comparison of $K_{e}$ and $T_{\mathfrak{t}}$ from urinary and serum data in eight experiments

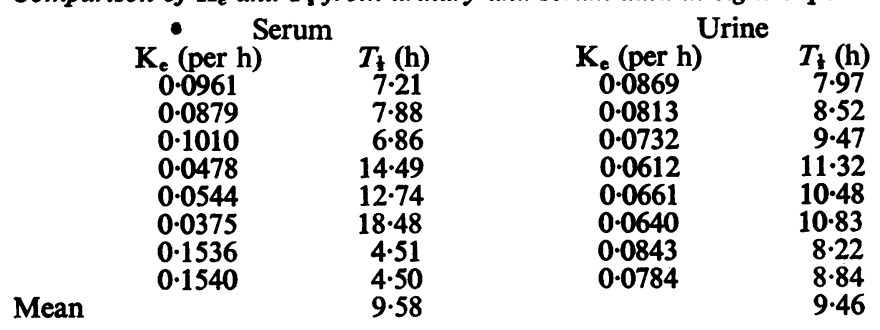

Four experiments were excluded from this analysis as serum data were inadequate. No significant difference exists between $T_{\xi}$ values derived from urinary or serum data.

\section{Drug concentrations and clearance}

Peak serum concentrations of amiloride were achieved at $4 \mathrm{~h}$ and averaged $47.5 \mathrm{ng} / \mathrm{ml}( \pm 13 \cdot 8)$. The mean cumulative urinary ${ }^{14} \mathrm{C}$ activity was $49 \cdot 8 \%$ $( \pm 10 \cdot 6)$ of the administered dose within the first 72 hours. Calculation of amiloride clearance was possible only where serum concentrations were reliable but exceeded simultaneously measured creatinine clearance.

Mean creatinine clearance for the twelve experiments during the period of diuresis (first $6 \mathrm{~h}$ after dosing) was $150 \mathrm{ml} /$ minute. Assuming that tubular water reabsorption removed $90 \%$ of the filtrate before the exchange site for sodium and potassium was reached, then the flow in the distal tubule was approximately $15 \mathrm{ml}$ per minute. At peak diuresis, urine flow averaged $2.5 \mathrm{ml} / \mathrm{min}$ and this implied that the distal concentration factor was approximately $6(15 / 2 \cdot 5)$. Urinary amiloride concentration ranged from 4-30 $\mu \mathrm{g} / \mathrm{ml}$ during diuresis which gave a drug concentration between $3 \mu \mathrm{M}$ and $20 \mu \mathrm{M}$ at the distal tubular site of action.

\section{Discussion}

This study demonstrated that there was no significant difference in the biological availability of the two amiloride formulations. Concentrations of $\left[{ }^{14} \mathrm{C}\right]$-amiloride in serum and urine were similar with both preparations to those reported earlier (Weiss et al., 1969). Pharmacokinetic parameters confirmed this similarity. Since amiloride is not metabolized, the unexcreted drug levels calculated from the urinary data gave estimates of $\mathrm{K}_{\mathrm{e}}, T_{\frac{1}{2}}$ and $\mathrm{V}_{\mathrm{d}}$. The $V_{\mathrm{d}}$ values were not consistent as the 
calculation includes an estimate of renal drug clearance derived in part from serum data, which were not completely reliable in four cases. Nevertheless, $V_{d}$ figures were considerably in excess of total fluid volume which suggested extravascular sequestration of amiloride. Similar evidence was obtained from animal experiments in which amiloride was concentrated in the gastro-intestinal tract (Baer et al., 1967).

In other studies, amiloride reduced short-circuit current and influx of sodium ions into isolated membranes capable of active sodium transport (Eigler, Kelter, Renner, 1967 ; Bentley, 1968 ; Salako \& Smith, 1970 a, b). The effective in vitro concentration was $0.1 \mu \mathrm{M}$ to $10 \mu \mathrm{M}$ and human urinary levels of $10 \mu \mathrm{M}$ have also been reported (Baer \& Foltz, 1969). From our data, the amiloride concentration was $3 \mu \mathrm{M}$ to $20 \mu \mathrm{M}$ in the distal renal tubule and was clearly sufficient to achieve a similar reduction in sodum transport.

The labelled $\left.{ }^{14} \mathrm{C}\right]$-amiloride was provided by Merck, Sharp and Dohme Ltd., and the radioactivity was measured in serum and urine by the staff of the Regional Medical Physics Department at Weston Park Hospital, Sheffield, and in faeces by the Department of Chemical Pathology at St. Mary's Hospital, London. We wish to thank Professor $\mathbf{H}$. Miller and Professor V. H. T. James for access to these counting facilities and their staff for help. We also acknowledge the technical assistance of Mrs. Sandra Smith and Mrs. Jacqueline Harlow. Professor John G. Wagner in the University of Michigan advised on the analysis of data, and Dr. M. F. Grayson helped in the experimental design.

\section{REFERENCES}

Baba, W. I., Lant, A. F., Smith, A. J., Townshend, M. M. \& Wilson, G. M. (1968). Pharmacological effects in animals and normal human subjects of the diuretic amiloride hydrochloride (MK-870). Clin. Pharmacol. Ther., 9, 318-327.

Baer, J. E. \& Foltz, E. L. (1969). Availability of amiloride at distal sites of action. Proceedings of IVth International Congress of Nephrology (Stockholm), p. 204.

Baer, J. E., Jones, D. B., Sprtzer, S. A. \& Russo, H. F. (1967). The potassium sparing and natriuretic activity of $\mathrm{N}$-amidino-3,5,-diamino-6-chloropyrazinecarboxamide hydrochloride dihydrate (amiloride hydrochloride). J. Pharmac. exp. Ther., 157, 475-485.

BeNTLEY, P. J. (1968). Amiloride: a potent inhibitor of sodium transport across the toad bladder J. Physiol., Lond., 195, 317-330.

Eigler, J., Kelter, J. \& ReNNER, E. (1967). Wirkungscharakteristika eines neuen acylguanidins. amiloride-HCl (MK-870) an der isolierten haut von amphibien. Klin. Wschr., 45, 737-738.

SAlako, L. A. \& Smith, A. J. (1970a). Effects of amiloride on active sodium transport by the isolated frog skin: evidence concerning site of action. Br. J. Pharmac., 38, 702-718.

Salako, L. A. \& SMITH, A. J. (1970b). Changes in sodium pool and kinetics of sodium transport in frog skin produced by amiloride. Br.J. Pharmac., 39, 99-109.

WAGNER, J. (1971). Biopharmaceutics and relevant pharmacokinetics. Hamilton: Drug Intelligence Publications.

Weiss, P., Hersey, R. M., Dujovne, C. A. \& Bianchine, J. R. (1969). The metabolism of amiloride in man. Clin. Pharm. Ther., 10, 401-406. 